\title{
RANCANG BANGUN PENDETEKSI PSIKOLOGIS SESEORANG BERDASARKAN DETAK JANTUNG BERBASIS KOMPUTER
}

\author{
Lalu Amam Hidayat*), Anton Yudhana*) \\ Program Studi Teknik Elektro Universitas Ahmad Dahlan Yogyakarta \\ Kampus 3, Jln. Prof.Dr. Supomo, Janturan, Yogyakarta 55164 \\ ${ }^{*}$ E-mai l: hidayatamam@gmail.com,eyudhana@ee.uad.ac.id
}

\begin{abstract}
Abstrak
Perkembangan ilmu pengetahuan dan teknologi di bidang elektronika dan instrumentasi dapat diciptakan alat-alat elektronik untuk menampilkan detak jantung. Namun perhitungan detak jantung masih dilakukan secara manual. Metode ini kurang akurat karena mengandalkan indra peraba manusia. Berbagai macam sensor yang digunakan untuk membantu menghitung detak jantung yaitu menggunakan pulse sensor. Penelitian ini menggunakan sensor heart rate yang diletakkan pada ujung jari. Cahaya $L E D$ menembus ujung jari diterima oleh rangkaian receiver kemudian diolah menjadi sebuah data digital oleh mikrokontroler Arduino Uno. Data yang diterima Arduino diteruskan melalui software processing untuk menampilkan keluaran pada layar komputer. Hasil penelitian berdasarkan data dari hasil pengujian adalah sensor heart rate mampu mendeteksi detak jantung saat kondisi rileks dan emosi. Detak jantung seseorang dalam keadaan emosi jumlah detaknya lebih banyak dibandingkan dengan keadaan rileks, karena saat emosi jantung memompa darah lebih cepat. Hasil pengujian menggunakan software processing berupa grafik dengan titik puncak P, Q, R, S, T.
\end{abstract}

Kata Kunci : Sensor Heart Rate, Mikrokontroler Arduino Uno, Processing, Komputer.

\begin{abstract}
Development of science and technology in the field of electronics and instrumentation can be created electronic devices to display heartbeat. Heartbeat calculation is still done manually. This method is less accurate because it relies on the human sense of touch. Various kinds of sensors are used to help calculate the heartbeat that is using a pulse sensor. This research uses heart rate sensors placed on the fingertips. Light from LED through the fingertip received by the receiver circuit is then processed into digital data by Arduino Uno microcontroller. Arduino received data through software processing to display the output on a computer screen. The research based on data from the test results is the heart rate sensor is able to detect heartbeat when conditions relax and emotion. The heartbeat of human in the emotional state more than the state relaxed, because when the emotion of the heart pumps blood faster. The test results using software processing in the form of a graph with the peak point $\mathrm{P}, \mathrm{Q}, \mathrm{R}, \mathrm{S}, \mathrm{T}$.
\end{abstract}

Keywords: Heart Rate Sensor, Arduino Uno Microcontroller, Processing, Computers.

\section{Pendahuluan}

Jantung merupakan organ manusia yang berfungsi memompa darah, jantung berkontraksi dimana satu siklus kontraksi biasanya disebut satu detak jantung [1]. Perhitungan detak jantung masih dilakukan secara manual yaitu dengan cara menghitung detak jantung di pergelangan tangan. Metode ini kurang akurat karena hanya mengandalkan indra peraba manusia Selain perhitungan detak jantung secara manual, metode yang sering digunakan adalah metode elektrik yaitu menggunakan Electrocardiograph (ECG) [2]. Alat ini umumnya sangat mahal dan penggunaannya cukup rumit sehingga masyarakat awam tidak bisa mengetahui kesehatan detak jantung mereka [3-5]. Penelitian ini menggunakan board Arduino dan sensor heart rate dikarenakan harga komponen ini relatif murah [6-8]. Hasil keluaran dari sinyal detak jantung ditampilkan pada display monitor laptop/ komputer. Gagasan untuk menggunakan komputer dalam mendeteksi detak jantung karena kegiatan ini membutuhkan rutinitas dan tingkat ketelitian sangat tinggi serta waktu antisipasi yang cepat.

\section{Metode \\ 2.1. Alat dan Bahan Penelitian}

Alat dan bahan dalam penelitian ini meliputi perangkat keras dan perangkat lunak untuk perancangan dan pengujian. Perangkat keras yang digunakan meliputi sensor heart ratem Arduino Uno dan rangkaian sistemnya.

Sensor heart rate adalah sensor detak jantung yang bekerja menggunakan prinsip photoplethysmography (PPG), yaitu metode non-invasive untuk mengukur detak jantung 
(cardiovascular) dengan mendeteksi volume aliran darah didalam nadi yang dekat dengan kulit. Adapun gambar dari sensor heart rate seperti Gambar 1.

Arduino Uno R3 adalah papan pengembangan (development board) mikrokontroler yang berbasis chip ATmega328P berfungsi sebagai prototyping circuit microcontroller.

Rangkaian minimum sistem mikrokontroler menggunakan Atmega8535 sebagai chipnya. Rangkaian minimun sistem yang digunakan adalah modul DT-AVR Low Cost Micro System buatan Innovative Elektronik. Bentuk fisik dari rangkaian minimum sistem seperti pada Gambar 2.
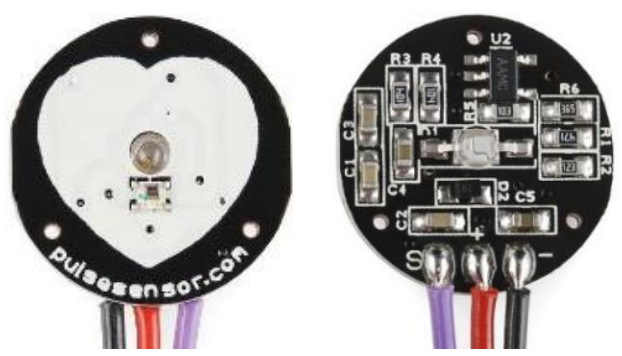

Gambar 1. Sensor Heart Rate

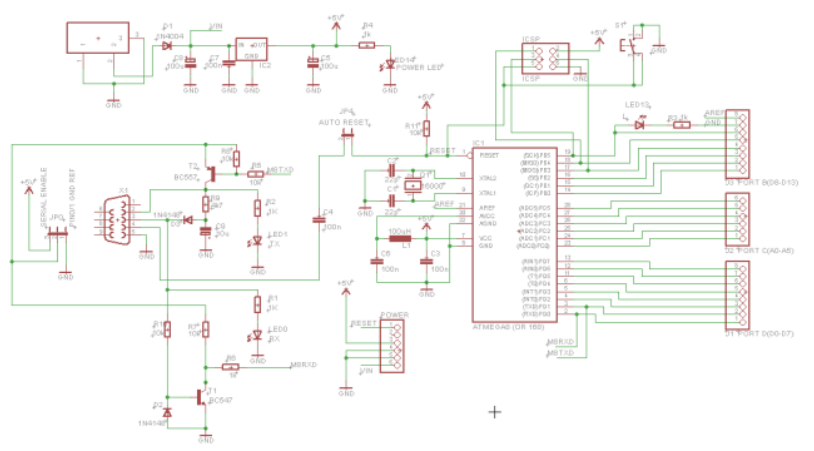

Gambar 2. Rangkaian keseluruhuan sistem mikrokontroler Arduino UNO Atmega328 [6]

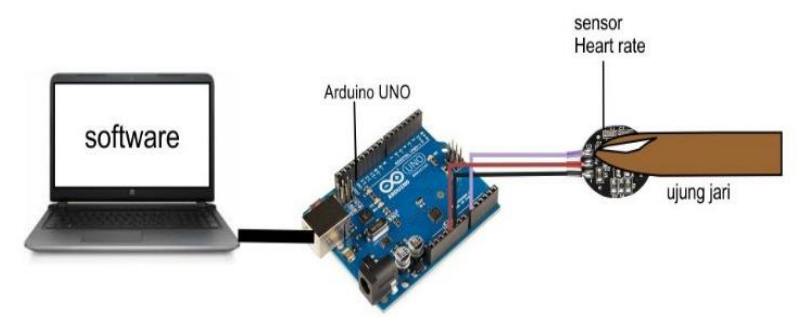

Gambar 3. Perancangan pendeteksi detak jantung

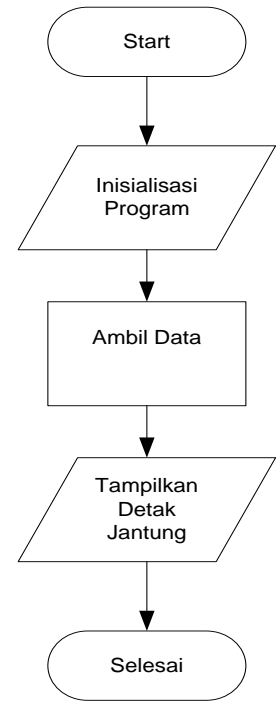

Gambar 4. Blok diagram proses kerja alat secara umum

\subsection{Perancangan Sistem}

Perancangan alat pendeteksi detak jantung secara umum adalah sensor heart rate dihubungkan ke Arduino dan hasil keluaran terlihat pada layar laptop/komputer, seperti ditunjukkan oleh Gambar 3. Blok diagram perancangan ditunjukkan pada Gambar 4.

Setelah program dimulai program melakukan inisialisasi pendeklarasian variabel, inisialisasi register, inisialisasi fungsi. Kemudian pada fungsi loop terjadi proses pengolahan data input sensor heart-rate, hasil pengolahan input sensor heart-rate menghasilkan output berupa detak jantung yang ditampilkan pada display monitor laptop/komputer. Berikutnya adalah proses dari Timer Interrupt program seperti Gambar 5.

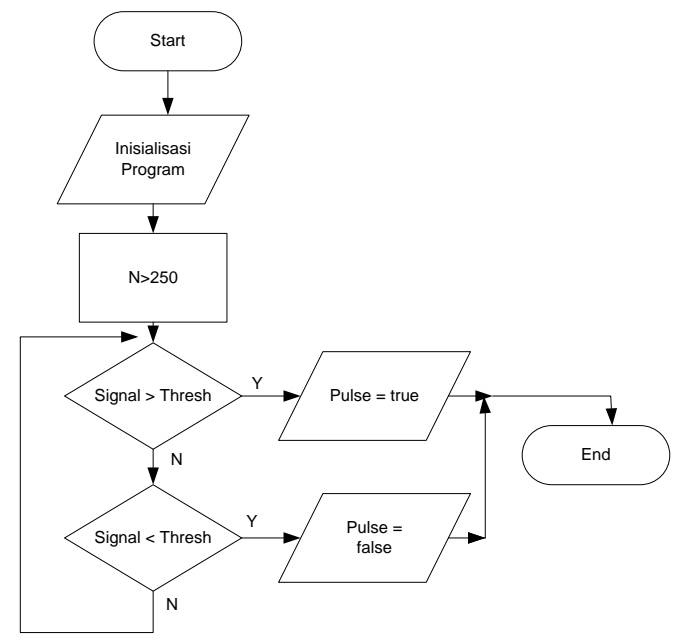

Gambar 5. Blog diagram timer interrupt 
Timer interrupt berfungsi menginisialisasi algoritma yang digunakan untuk menemukan sinyal detak jantung. Variabel $\mathrm{N}$ merupakan variabel yang berfungsi untuk memonitor waktu detak jantung terakhir untuk menghindari adanya noise atau gangguan. Nilai variabel $\mathrm{N}$ ditentukan nilai dari variabel sampleCounter dikurangi nilai variabel lastBeatTime. Ketika nilai variabel signal lebih besar dari nilai variabel thresh, sensor mendeteksi adanya pulsa detak jantung. Namun jika nilai variabel signal lebih kecil dari nilai variabel thresh, sensor tidak mendeteksi pulsa detak jantung.

\section{Hasil dan Analisis}

Tahap pengujian pertama adalah pegujian rangkaian Arduino, pengujian ini diambil data berupa tegangan keluaran rangkaian Arduino Uno. Tahap pengujian kedua adalah pengujian software Arduino IDE dan software processing. Pengujian ini bertujuan untuk melakukan compiling program dengan baik atau tidak. Tahap pengujian ketiga adalah pengujian alat secara terpadu.

\subsection{Pengujian Arduino Uno}

Pengujian ini untuk memastikan kinerja rangkaian mikrokontroler Arduino Uno dengan menggunakan multimeter digital. Mekanisme pengukuran tegangan keluaran rangkaian Arduino Uno dapat dilihat pada Gambar 6.

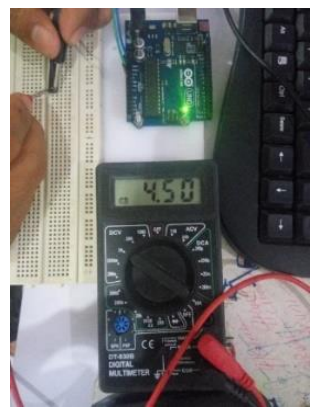

Gambar 6. Mekanisme pengukuran tegangan keluaran Arduino

Tabel 1. Hasil pengujian tegangan keluaran Arduino

\begin{tabular}{ccccc}
\hline No & $\begin{array}{c}\text { Jenis } \\
\text { Regulator }\end{array}$ & $\begin{array}{c}\text { Tegangan } \\
\text { Input (Volt) }\end{array}$ & $\begin{array}{c}\text { Tegangan } \\
\text { Output (Volt) }\end{array}$ & Keterangan \\
\hline 1. & IC AMS 117 & 5,00 & 4,50 & Sesuai \\
\hline
\end{tabular}

Berdasarkan mekanisme pengukuran tegangan keluaran Arduino, didapatkan hasil pengukuran tegangan keluaran seperti Tabel 1.

Tegangan keluaran IC AMS 117 Arduino adalah 4,50 volt. Tegangan tersebut sesuai dengan tegangan kerja rangkaian Arduino, sehingga output tegangan dapat didistribusikan ke setiap masing-masing pin input/output Arduino.

\subsection{Pengujian Software Arduino IDE}

Pengujian software yang pertama adalah menguji kemampuan software Arduino IDE ketika melakukan proses compiling. Mekanisme pengujian software seperti Gambar 7.

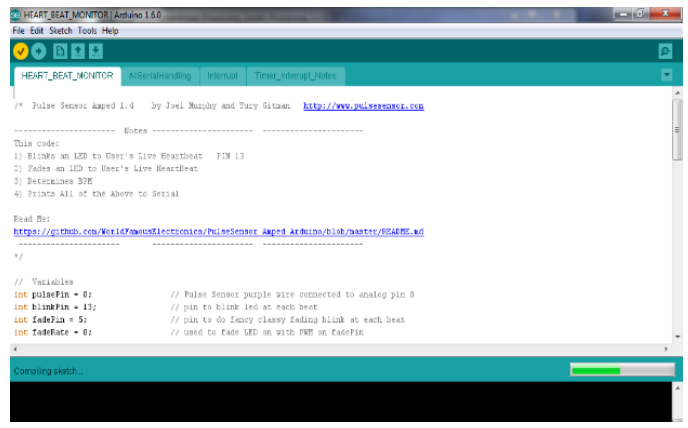

Gambar 7. Proses compiling pada Arduino IDE

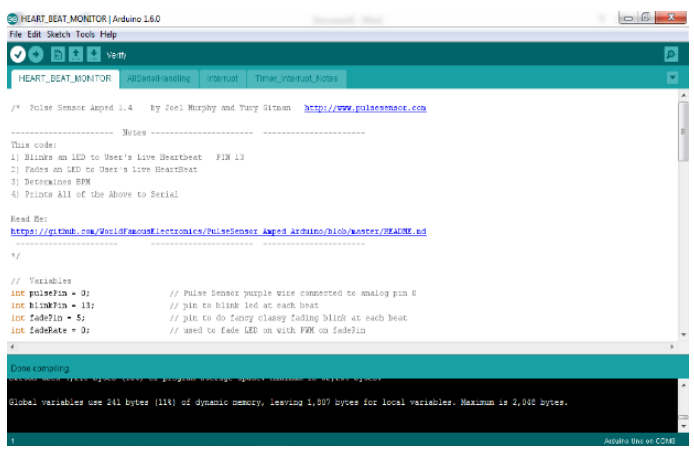

Gambar 8. Komentar ketika Arduino IDE selesai melakukan compiling

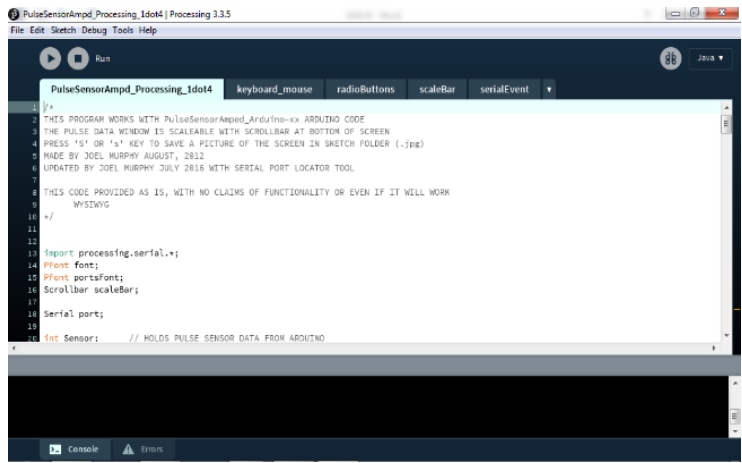

Gambar 9. Proses compiling dan run

Arduino IDE sedang melakukan proses compiling. Setelah melakukan compiling selanjutnya muncul proses Arduino telah melakukan compiling seperti Gambar 8.

\subsection{Pengujian Software Processing}

Pengujian software yang kedua adalah melakukan pengujian software processing. Penelitian software 
processing untuk mendesain tampilan hasil pendeteksian detak jantung yang ditampilkan pada laptop/komputer. Mekanisme pengujian software processing seperti Gambar 9.

\subsection{Pengujian Alat Pendeteksi Detak Jantung Secara Terpadu}

\subsubsection{Pengujian Respon Sensor Heart Rate Terhadap} Detak Jantung

Pengujian ini dilakukan untuk menguji kemampuan sensor heart rate mendeteksi detak jantung. Adapun respon sensor ketika tidak ada detak jantung seperti Gambar 10.

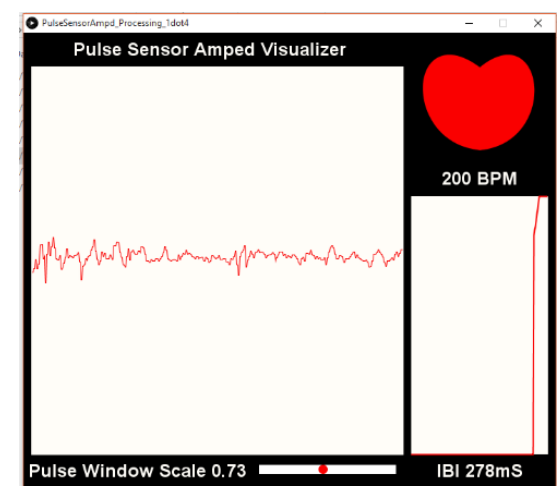

Gambar 10. Pengujian respon sensor heart rate tanpa ada detak jantung

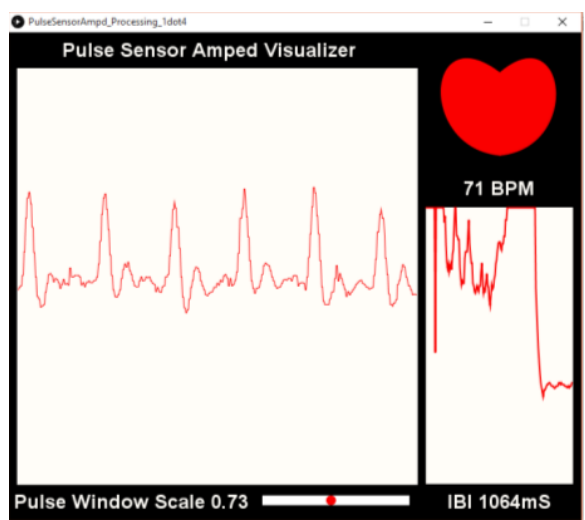

Gambar 11. Pengujian respon sensor heart rate terhadap detak jantung

Kondisi gelombang ketika sensor heart rate tidak mendeteksi detak jantung. Gelombang yang ditampilkan sangat kecil, dikarenakan sensor heart rate tidak mendeteksi detak jantung. Selanjutnya respon sensor ketika mendeteksi detak jantung seperti Gambar 11.

Kondisi gelombang ketika sensor heart rate mendeteksi detak jantung. Gelombang yang ditampilkan terlihat stabil dikarenakan sensor heart rate telah mendeteksi detak jantung dengan baik.

\subsubsection{Pengujian Sensor Heart Rate dengan Titik Objek yang Berbeda}

Tahap ini sensor heart rate diletakkan di dua titik objek yang berbeda yaitu ujung jari dan daun telinga untuk membandingkan keluaran hasil dari detak jantung. Adapun gambar pengujian sensor heart rate dengan titik objek berbeda seperti Gambar 12.

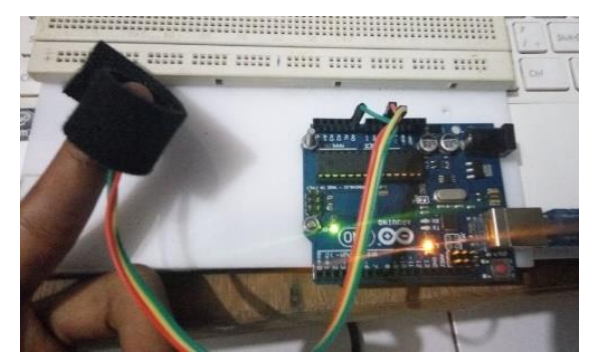

Gambar 12. Pengujian sensor heart rate pada ujung jari
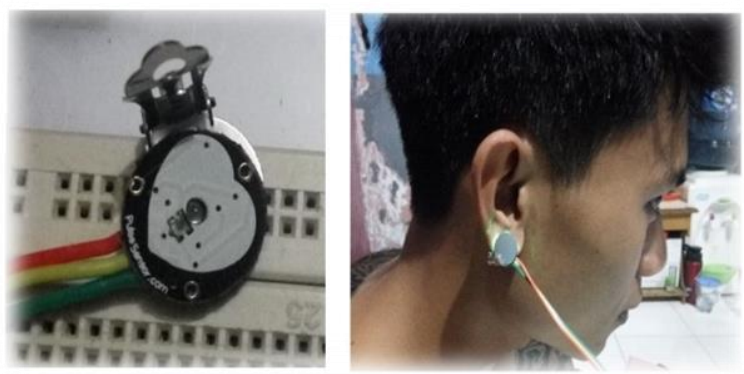

Gambar 13. Pengujian sensor heart rate pada daun telinga

Tabel 2. Hasil pengujian sensor heart rate pada objek ujung jari dan daun telinga

\begin{tabular}{ccccc}
\hline No & Nama & Usia & Detak Jantung & IBI (mS) \\
\hline 1 & 85 & 69 & 11 & 1 \\
2 & 75 & 70 & 5 & 2 \\
3 & 60 & 73 & 13 & 3 \\
4 & 58 & 73 & 15 & 4 \\
5 & 55 & 74 & 19 & 5 \\
\hline
\end{tabular}

Pengujian sensor heart rate dilakukan dengan meletakkan sensor di salah satu ujung jari kemudian diolah oleh Arduino menjadi sebuah data digital dan ditampilkan melalui software processing. Selanjutnya pengujian sensor pada daun telinga seperti Gambar 13.

Pengujian respon sensor heart rate dengan meletakkan sensor pada daun telinga. Setelah melakukan pengujian respon sensor heart rate pada ujung jari dan daun telinga didapatkan hasil berupa nilai dari detak jantung Beat PerMinute (BPM). Berikut hasil pengujian respon sensor heart rate seperti Tabel 2.

Berdasarkan hasil pengujian respon sensor heart rate terdapat perbedaan jumlah detak jantung objek ujung jari dan daun telinga. Untuk hasil rata-rata jumlah detak jantung ujung jari sebagai berikut: 
Rata - rata detak jantung ujung jari $=$ Jumlah detak jantungujung jari

Maka:

Maka: Jumlah percobaan

Rata - rata detak jantung ujung jari $\frac{333}{5}=66,6$

BPM

Sedangkan rata-rata pehitungan detak jantung daun telinga sebagai berikut:

Rata - rata detak jantung daun telinga $=$ $\underline{\text { Jumlah detak jantung daun telinga }}$

Maka:

Rata - rata detak jantung pada daun telinga $\frac{359}{5}=$ 71,8 BPM

Terdapat selisih antara hasil pendeteksian sensor heart rate dengan objek ujung jari dan daun telinga. Menghitung ratarata selisih dari detak jantung dengan objek yang berbeda seperti rumus berikut:

Rata - rata selisih objek $=\frac{\text { Jumlah } \operatorname{selisih}}{\text { Jumlah percobaan }}$

Maka :

Rata - rata selisih $=\frac{63}{5}=12,6 \mathrm{BPM}$

\subsubsection{Pengujian Alat Terhadap Psikologis Seseorang}

Pengujian dilakukan untuk mengetahui detak jantung berdasarkan kondisi psikologis seseorang. Pengujian dilakukan berdasarkan dua parameter yaitu kondisi rileks dan emosi [9-10]. Adapun hasil pengujian detak jantung berdasarkan kondisi rileks dan emosi seperti Gambar 14.

Hasil pengujian alat pada objek dalam kondisi rileks. Jumlah detak jantung setiap menitnya adalah 85 Beat PerMinute (BPM) dan Inter Beat Interval (IBI) $782 \mathrm{mS}$ [11]. Adapun hasil pengujian detak jantung saat kondisi emosi seperti Gambar 15.

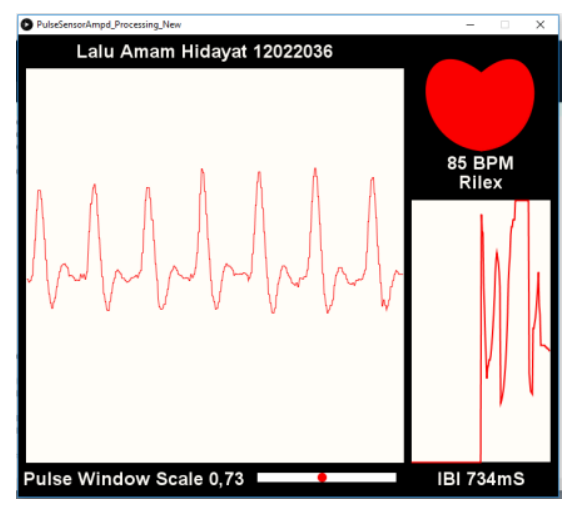

Gambar 14. Pengujian alat detak jantung pada kondisi rileks

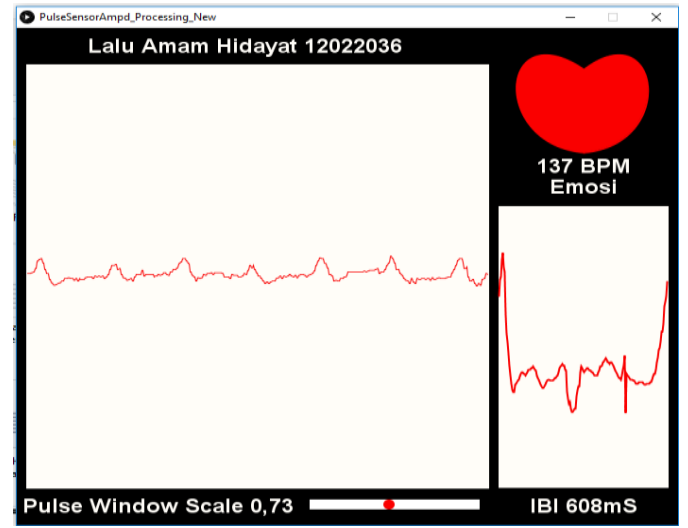

Gambar 15. Pengujian alat detak jantung pada kondisi emosi

Tabel 3. Hasil pengujian alat pada kondisi rileks

\begin{tabular}{ccccc}
\hline No & Nama & Usia & Detak Jantung & IBI (mS) \\
\hline 1 & A & 20 & 85 & 734 \\
2 & B & 21 & 60 & 1128 \\
3 & C & 23 & 58 & 1062 \\
4 & D & 20 & 75 & 808 \\
5 & E & 23 & 55 & 1018 \\
\hline
\end{tabular}

Tabel 4. Hasil pengujian alat pada kondisi emosi

\begin{tabular}{ccccc}
\hline No & Nama & Usia & Detak Jantung & $\mid \mathrm{IBI}(\mathrm{mS})$ \\
\hline 1 & $\mathrm{~A}$ & 20 & 137 & 608 \\
2 & $\mathrm{~B}$ & 21 & 116 & 802 \\
3 & $\mathrm{C}$ & 23 & 108 & 582 \\
4 & $\mathrm{D}$ & 20 & 148 & 252 \\
5 & $\mathrm{E}$ & 23 & 116 & 784 \\
\hline
\end{tabular}

Jumlah dari hasil detak jantung saat kondisi emosi adalah 137 Beat PerMinute (BPM) dan Inter Beat Interval (IBI) $608 \mathrm{mS}$ [11]. Setelah melakukan pengujian alat pada kondisi rileks dan emosi, didapatkan hasil berupa nilai dari detak jantung. Data hasil pengujian alat disajikan pada Tabel 3 dan Tabel 4. Hasil pengujian kondisi rileks detak jantung berkisar antara 60 sampai 70 Beat PerMinute (BPM).

Hasil pengujian pada kondisi emosi detak jantung berkisar antara 100 sampai 140 Beat PerMinute (BPM).

Dari hasil penelitian dilakukan proses analisis data hasil pengujian alat. Detak jantung yang diteliti merupakan data yang terdiri dari $\mathrm{P}, \mathrm{Q}, \mathrm{R}, \mathrm{S}$, dan T seperti Gambar 16 dan 17. 
Gelombang detak jantung saat kondisi rileks. Sesuai syarat menentukan satu gelombang didapatkan titik puncak $\mathrm{P}, \mathrm{Q}$, $\mathrm{R}$, S dan T. Setiap dimulai satu gelombang grafik gelombang terlihat sedikit naik dikarenakan sensor heart rate menerima sinyal detak jantung. PQ interval merupakan perlambatan sinyal. Perlambatan ini memberikan waktu atrium untuk mengosongkan darah di dalamnya ke dalam ventrikel. Sinyal ini menuju titik Q melalui atrium menyebabkan kedua atium berkontraksi dan mendorong darah ke ventrikel di bawahnya. Gelombang $\mathrm{R}$ adalah puncak detak jantung berkontraksi dan memompa darah ke paru-paru. Setelah detak jantung berkontraksi terjadi selang waktu menuju detak jantung selanjutnya sampai titik S. Titik puncak T merupakan proses ketika ventrikel mengalami repolarisasi.

Titik R menunjukkan grafik yang tinggi, dikarenakan saat emosi kecepatan jantung untuk memompa darah ke paruparu dan seluruh tubuh sangat cepat dibandingkan dengan titik R saat kondisi rileks.

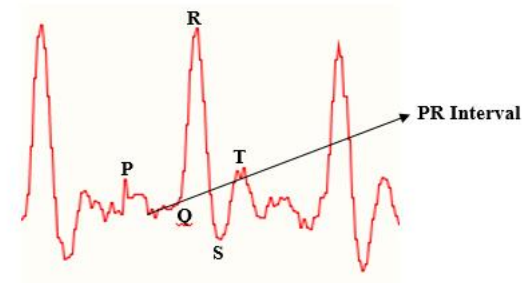

Gambar 16. Gelombang detak jantung berdasarkan P, Q, R, $\mathrm{S}$ dan $\mathrm{T}$ rileks

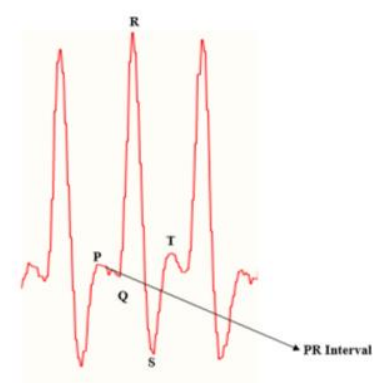

Gambar 17. Gelombang sinyak detak jantung pada kondisi emosi

\section{Kesimpulan}

Berdasarkan hasil penelitian disimpulkan bahwa, alat bekerja dengan baik dibuktikan respon alat terhadap detak jantung sudah dapat ditampilkan pada komputer/laptop. Perbedaan hasil keluaran antara detak jantung saat kondisi rileks dan emosi terletak pada jumlah detak jantung, jumlah detak jantung normal saat rileks berkisar antara 60 sampai 90 Beat PerMinute (BPM) sedangkan detak jantung saat kondisi emosi berkisar antara 90 sampai 150 Beat PerMinute (BPM). Perbedaan lain adalah ketika kondisi emosi titik puncak $\mathrm{R}$ lebih tinggi dibandingkan kondisi rileks dikarenakan proses pemompaan darah pada jantung lebih cepat saat kondisi emosi.

\section{Referensi}

[1]. Wijaksono YA, Kemalasari, \& Rokhana R. Rancang Bangun Alat Pendeteksi Stress Menggunkan GSR dan Detak Jantung. Teknik Elektronika - Politeknik Elektronika Negeri Surabaya. ITS Surabaya Indonesia. 2013.

[2]. A Rizal, MA Riyadi. "FPGA-based system for countinous monitoring of three vital signs of human body", 2nd International Conference on Information Technology, Computer, and Electrical Engineering (ICITACEE), Semarang, Indonesia, 2015, hal. 221-226

[3]. Suari M. Rancang Bangun Alat Penampil Sinyal Denyut Jantung Berbasis PC Dengan Sensor Fotodioda. Fakultas Matematika dan Ilmu Pengetahuan Alam. Universitas Andalas. Padang. 2009.

[4]. Nursidik A. Studi Eksperimen Berbasis pada Penggunaan LED IR dan $R$ Untuk Menentukan Rasio Sinyal Detak Jantung Sebagai Model Pembelajaran Latihan Penelitian Materi Optic. Universitas Ahmad Dahlan. Yogyakarta. 2013.

[5]. MA Riyadi, IA Iskandar, A Rizal, "Development of FPGAbased three-lead electrocardiography", Proceeding of International Seminar on Intelligent Technology and Its Applications (ISITIA 2016), Lombok, Indonesia, 28 Jul $30 \mathrm{Jul}$ 2016, hal. 67-72.

[6]. Anton Y, Bayu K. Pengaturan Suu Kelembapan Ruangan dan Penyiraman Otomatis Tanaman Hidroponik Berbasis Arduino Uno. Teknik Elektro Universitas Ahmad Dahlan. Yogyakarta. 2017.

[7]. Erliyanto M, Sumaryo S, \& Rizal A. Perancangan Perangkat Monitoring Denyut Jantung (Heart Beat Monitoring) Dengan Visualisasi LCD Grafik Berbasis ATMEL AT89C51. Teknik Elektro Institut Teknologi Telkom. Bandung. 2008

[8]. Adiguna B, Rizal A, \& Hanafi UB. Aplikasi Pengukuran Denyut Jantung Janin Berbasis Ultrasonic Doppler Fetus Monitor. Teknik Telekomunikasi, Fakultas Teknik Elektro. Universitas Telkom. 2007.

[9]. Herlina DT, Hanna AP, Suryasatra T, Bambang S. "Pola Distribusi Interval Detak Jantung Dengan Memanfaatkan Jumlahan Fungsi Gauss Yang Dioptimasi Secara NelderMead Simplex." Prosiding Seminar Nasional Sains dan Pendidikan Sains IX, Fakultas Sains dan Matematika, UKSW Salatiga, 21 Juni 2014, 2014, hal. 739-747 .

[10]. RG Landaeta, O Casas, and RP Areny. Heart rate detection from plantar bioimpedance measurements. 28th IEEE EMBS Annual International Conference, USA. 4547. 2006.

[11]. Mayangsari AS. Healty Service. Penerbit: PT Gramedia Pustaka Utama. Gedung Gramedia Blok I lt 5 J. Palmerah Barat 29-33, Jakarta 10270. 57-61. 2005. 